\title{
SOME ASPECTS OF TECHNICAL AND CRIMINALISTIC ASSISTANCE IN MURDER CRIMINAL CASE BY SHOOTING Dumitru GOŞA
}

\author{
Department of Forensic Services of the I.P.J. Sibiu, Romania \\ dan.gosa@yahoo.com
}

\begin{abstract}
The role and importance in solving the crime scene investigation of offences against life resulting from forensic science that puts the reach of judicial bodies and the technical-scientific methods necessary for discovering, fixation, lifting, turning and examining traces of homicide, author and victim identification.

Forensic and technical assistance for the offence of murder committed by shooting, assumes that the technical, legal ballistic investigation is carried out on the basis of principles aimed at forensic identification, and using methods and procedures in other sciences related (physics, chemistry, biology, microscopy comparison, shooting invisible radiation, spectral analysis, etc.).

Therefore, complex issues and complex collection of evidence and material resources and the sample is treated from a multidisciplinary perspective.

Clarifying all the circumstances relating to the death of a person, and identifying and proving the guilt of infringing the right to life cannot be achieved today without the involvement of forensic experts and specialists and the usage of scientific-technical means they have.

In this regard, recent scientific findings adopted by the forensics of Romania (eg Motorola Printrak AFIS databases Bis, IBIS, IMAGETRAK database of genetic analysis laboratories physic-chemical micro traces), supplemented by professional criminologists decisively contribute to solving homicide by gunshot.
\end{abstract}

Keywords: firearm, spectral analysis, ballistics judicial databases, construction of firearms, seal, body, firing distance, main and secondary signs of withdrawal

\section{Introduction}

The right to life is a fundamental human right, which by its importance goes beyond personal interest, with relevance for the entire society.

Protecting the right to life finds its consecration by international standards primarily, but also internal norms of criminal law, given the importance the life of a person has not only for her, but for the whole society.

Thus, article 3 of the Universal Declaration of Human Rights adopted by the UN General Assembly on 10 December 1948, provides that "Everyone has the right to life, liberty and security of person" [1]. Given the importance the right to life has been included in the fundamental law of each state. Constitution in article 22, paragraph 1, provides that "The right to life and the right to physical and mental integrity of person are guaranteed" [2].

A significant contribution to the protection of this right is a criminal law that is actually legal framework designed to provide effective protection of the right to life.

The forensic investigation of a murder differs from other types of crime, through its specific issues, established in several main areas, namely: establishing cause and 
nature of death, the circumstances of time and manner in which the act was committed, discovering means or instruments used to suppress the victim's life, identify the author, the prospective participants to commit murder, stating the purpose or motive of the crime.

In times of rising crime in recent years regarding crimes committed with firearms both in our country and especially in the European Union is required a serious approach and high practical utility of this "mode of operation".

\section{The importance of forensic investigations and forensic medical examination}

Technical assistance forensics of where an offence of murder by shooting was committed is among the most important activities that contribute to the goal of the criminal trial.

Slightly met by December 1989 gunshot murder lately experienced an alarming increase causing serious trouble in its investigation by the prosecution.

Judicial practice has shown that when forensic investigative activities were carried out and completed by the rules and established procedures adapted to the individual case, succeeded truth, identifying the perpetrator and prove his guilt.

In general, by "traces of firearms" we understand the changes that occur on objects, including the human body, after using them, as a result of dynamic, thermal and chemical phenomena accompanying the shot [3].

In order to understand the concept of "traces of firearms" we should start from the notion of "firearm" as defined by the legislation, namely those weapons whose operation determines the throwing of one or more projections, lighted or bright substances or spreading harmful, irritating or neutralizing gases [4].

The operational principle of such weapons is based on the expansion force of the gas from the explosion or detonation of a load staples.

Firearms perform aggression remotely, the violence being invented by man par excellence and thereby raise a number of issues which are of particular importance in judicial investigations and forensics.

The research on firearms and shooting conditions belong to the forensic and legal medicine alike. On the basis we find the scientific and technical methods and also the principles of identifying forensic traces. Will be methodically analyzed the ammunition, powders, tubes burned projectiles fired, penetration and exit openings and all traces and phenomena related to the use of a firearm in a criminal event, in order to identify: the murder weapon, given that fired this weapon, the time when a person was shot and the shooter.

Knowing how to present products gunshot injuries is essential to the prosecution, to distinguish them from the wounds caused by other vulnerable agents, including to sense if the question is about a murder or about a suicide.

To highlight traces produced by shooting and discovered the victim's body to be known that they are classified into two major categories traces of gunshot main and secondary tracks, which are subject to the type of weapon, ammunition used, the distance from which shot angle drawing etc. The important element is the bullet (made up of the following components: the bullet itself, which has a cylindrical shape ending in a pointed arch and consists of lead and dressed in a shirt resistant metal; cartridge, which is fastened the base of the bullet which is loaded with the powder; staple, located at the bottom bullet containing mercury fulminate, chemical which comes to percussion) which exerts on the human body four actions:

- penetration, forming a round or oval inlet with loss of substance;

- $\quad$ subsidence, when the force life is low (at the end of the path), only the tissue as the bullet split wedge, to form an inlet slit-shaped, corresponding to the direction of elastic fibers in the skin;

- concussion, the lifeblood is very small, 
the bullet can act as a hard object blunt produce the inlet, but bruising or excoriation;

- breaking, this action occurring when dragging is close, the bullet having a very large living force. In this case, due to the action gas inlets may be incurred loose, broken and radial cracks.

In general, the inlet is smaller than the caliber of the bullet because the skin retracted. However, this hole may be equal in size to the caliber of the bullet when the skin is located on the bone, as happens in the skull, where the skin becomes clogged less.

The inlet is greater than the caliber of the bullet in shooting from near or by stuck pipe. In far shootings the inlet is round; it can be oval when the bullet does not penetrate perpendicular, but in an arbitrary angle, or because of skin elasticity.

At the entrance of the bullet hole can be observed a number of changes that occur constantly, regardless of the distance of the shot and is due to primary factors:

They are [5]:

- the flange of excoriation, which is a little short of the substance to the inlet lip. The explanation for the producing of this excoriation is: chorion being more elastic than the epidermis, it breaks before chorion and around the wound, on a distance of 1-2 $\mathrm{mm}$ from the edges of the hole. At a living person, the excoriation or collar of corrosion is colored red. Instead on a corpse as it is a lack of substance, this pigments itself;

- removal collar (defilement) is due to deletion bullet hole edges, these edges resulting charging not burnt powder particles, grease, smoke, items that are on the bullet casing;

- ring metallization, due to deletion of edges inlet bullet here depositing small metal particles are driven by bullet after its friction in the pipe.

Passing through the body, the bullet loses a significant amount of power, so at the exit it acts like a feather on the skin, loosening it in the slot-shaped sides.

Therefore, at the exit wound we do not find a loss of substance, so that it will not present the body pigmentation edges [6].

The exit wound size can be smaller than the bullet when the skin retracts or it can be equal to it.

For the inlet to be equal to the outlet, the projectile must pass through the body with great speed, to be animated by a sharp helical motion to penetrate materials of the same density and do not deform after penetration trajectory.

For the inlet to be greater than the outlet it requires that the projectile enters obliquely and out perpendicular to the incoming train foreign body which then abandons it and the inlet channel to act and gases.

In order for the inlet to be smaller than the outlet, it has to enter once the projectile trajectory is deformed by increasing its volume, or an angle between perpendicular and out.

Also, this aspect occurs when the projectile causes at the exit bone dodges.

The search for ballistic and forensic trace materials is based on thorough examination conducted on the position of the victim, of the way it was shot, given the distance from which could be shoot, the type of weapon and munitions employed.

The victim's body will be examined in the position it is found. The victim's position and all these findings must be located in sketches and a series of photographs and metric guidance before going to the body.

Also to examine the traces of gunshot, to set the direction, distance and angle of the shooting and clarify the various circumstances of the murder, the prosecution and experts on the field must take into consideration other factors, including the elements of the shoot which are really important.

It is a well known fact that any deterioration represents a result of the mutual action of the deteriorating factor and of the deteriorated environment.

In case of a death caused by fire weapons as in the case of all the injuries for that 
matter -, the determining factors in relation with the shooting distance are owed, on one hand, to the action of the bullet and of the gas produced by the powder resulting during the shot, and, on the other hand, to the action of the gas produced by the explosive load of certain bullets with a special destination.

The nature of these deteriorations can however bear essential changes, firstly generated by the shooting distance.

As we have mentioned above, the external injuries on the victim's body - caused by the shooting - are the orifice of entry, the channel, and the orifice of exit.

The surface traces of the ricochets are represented either by scratches, or by lowdepth crevasses, created by the hit of the flying bullet.

Ricochet traces are characterized by the fact that, at the time of the ricochet, the bullet moves away from the hit object, losing both its speed and its direction at the same time.

The discovery of the gun is, without a doubt, one of the most important tasks of the investigation at the scene of the crime.

Judiciary practice offers numerous examples when, in order to evade responsibility, the doer hurries to abandon the gun used to commit the murder, and in such cases, one must examine carefully the place where the victim was found, as well as the place where the shooter was standing, determined based on the existing data.

If the gun is discovered at the scene of the crime, it will be recorded firstly by means of photographs - and subsequently in the findings minutes -, by writing down its distance and position as compared to the surrounding objects, as well as to the body.

Concurrently, one must specify the direction in which the gun was oriented, the position of the hammer and of the loader, whether the gun was blocked or not.

After having set the gun in the field of the offence, one must proceed to its preliminary examination. Firstly, one must verify whether the gun was loaded or not, operation which must be carried out with extreme care in order to avoid any accidents.

Also, the gun must be lifted with maximum prudence, in order not to destroy the eventual digital traces existing thereon.

If the gun is found in the victim's hand or near the victim, the situation of the gun must be recorded also in a metrical photograph. On this occasion, one must never neglect the verification of the place where the gun is situated and of the surrounding area with the magnifying glass, in order to determine whether the gun was placed in that spot, if it fell there or if it was slammed down, being a known fact that, in this latter case, characteristic traces may remain on the gun, and also characteristic signs in the falling place of the gun.

One can proceed to the lifting of the gun and turning of the body only after having determined all the above.

The examination of the gun is an issue of the forensic lab, and the lifting and transportation of the gun is one of the actions that must be conducted with great care by the criminal investigation authorities.

It can only be examined in perfect conditions at the scene of the crime, due to the fact that such an exam requires means and techniques that can only be made available by a forensic lab.

Only a brief examination of the gun can be conducted at the scene of the crime, aiming at finding the digital or palm papillary traces, traces of blood or other traces that might be found on the surface of the gun.

In case of murders committed with fire weapons, the discovery of the gun is one of the important tasks of the investigation at the scene of the crime. It must be sought in the vicinity of the body, as well as in the places where the doer left any traces, or on the access ways.

Sometimes, the gun can be found in wells, streams, buried in the ground, in the tree hollows, etc. Shot cartridge cases must be sought starting from the area where the doer is suspected to have stood.

Bullets can be found in various places, depending on the circumstances in which 
the deed was committed: in the walls, in the ceiling, in the furniture from the room, on the floor or in the floor, in the door and window cases, in the victim's clothes, in the body or in other places - vehicles, trees, fences, etc.

The discovery of the fire weapons and of the ammunition has no difficulties in case of suicides and of attempts of dissimulation of the murder in a suicide. In most cases, the doer will attempt to abandon the gun, either by hiding it or by throwing it away.

Buried guns are looked after by using metal detectors, and those thrown in streams, wells, latrines must be sought by using powerful electromagnets.

Guns hidden in concrete or brick walls, in various compact objects of a certain density are sought by using gamma-grapher installations or portable Röentgen devices.

All these, corroborated with the lesions on the body are fundamental elements in the determination of the direction, shooting distance, and shooting angle, enabling the accurate determination of the place where the gun was shot.

After having recorded the position of the body and of the gun by metrical photographs, and after having lifted the gun in view of conducting the lab exam, the body may be turned.

As soon as the body was turned or moved, one must proceed to the determination of the situation regarding blood leakages from under the body and of their relation with the blood stains on the clothing by means of a metrical photograph.

Orifices in the clothes and their surrounding areas will be examined very carefully with a powerful magnifying glass; their aspect must be described before any movement, and possibly one will proceed to photographing them at the very scene of the crime.

These orifices must be especially preserved, protected from friction and moisture, in order to enable them to be the object of other lab exams as well.

At their turn, the secondary traces of the shooting appear as result of the thermal and chemical phenomena that take place inside the barrel, and at a certain distance from them. Unlike the main traces - which can be found at all times -, secondary traces cannot be emphasized entirely.

Knowing the above presented facts, upon the examination of the body, the criminal prosecution authority must describe thoroughly the orifice of entry - or the orifices of entry -, the area of the body where they are situated, the outer image of the lesions, the orifices of exit, as well as the secondary traces of the shooting: burns around the orifice of entry, traces resulted from the action of the gas, those of soot, of unburned powder, metal particles separated from the projectile upon perforation or particles found on the edge of the orifice of entry by friction or traces of grease.

\section{Conclusions}

In conclusion, in order to find the truth with respect to a death suspected to have occurred by shooting a person, a multitude of technical-forensic activities must be carried out, which must be corroborated among themselves.

Forensic investigation, in case a human body has been discovered, will clarify several issues, starting from the investigation at the scene of the crime, identifying and listening to the persons that may provide information of operative interest concerning the victim and the author as well as the circumstances in which the event took place, clarification of controversial circumstances, ordering the forensic findings and surveys, etc.

It is essential for the forensic specialists and experts to have thorough knowledge of all the categories of traces that can be discovered at the scene of the crime, the manner of correct interpretation of the aspects found upon the investigation at the scene of the crime, so that the results of the forensic investigation of the scene of the crime lead to the elaboration of certain pertinent versions and eventually to finding the truth in the criminal case. 


\section{References}

[1] Universal Declaration of Human Rights, adopted at the United Nations General Assembly, at December 10, 1948.

[2] Romanian Constitution from data 21. 11. 1991, amended by Law Review, No. 429 from 2003, Title II, Chapter II, Article 22.

[3] Măcelaru Vasile, Judicial Ballistics, Bucharest, 1972, p. 16-21.

[4] Măcelaru Vasile, Judicial Ballistics, Bucharest, 1972, p. 69.

[5] Beliş Vladimir, Forensic Medicine in Judicial Practice, Publishing House Juridică, Bucharest, 2003, p. 166-167.

[6] Beliş Vladimir, Forensic Medicine in Judicial Practice, Publishing House Juridică, Bucharest, 2003, p. 169.

\section{Bibliography}

Beliș Vladimir, Forensic Medicine in Judicial Practice, Publishing House Juridică, Bucharest, 2003.

Criminal and Criminal Procedure Code of Romania.

Romanian Constitution from data 21. 11. 1991, amended by Law Review, No. 429 from 2003, Title II.

Universal Declaration of Human Rights, adopted at the United Nations General Assembly, at December 10, 1948.

Emilian Stancu - Forensic Treaty, Publishing House ACTAMI, Bucharest, 2001.

Lazăr Cârjan - Forensic Treaty - Publishing House Pinguin Book, Bucharest, 2005.

Măcelaru Vasile, Judicial Ballistics, Bucharest, 1972.

Forensic Magazine, years 2000-2014.

Uţică Vasile, Dr. Florescu Bujor, Investigation and research of high violent crimehomicide-, Publishing House M.A.I., Bucharest, 2003. 